\title{
ANALISIS PENGARUH PENERAPAN TOTAL QUALITY MANAGEMENT (TQM) TERHADAP KINERJA KARYAWAN LABORATORIUM DI PT.X
}

\author{
Niken Septiani Kurnia ${ }^{1}$, Raden Faris Gumelar ${ }^{2}$, Rifki Hidayattulloh ${ }^{3}$ \\ Jurusan Teknik Industri \\ Universitas Widyatama \\ Jl.Cikutra No.204A, Bandung \\ niken.septiani@widyatama.ac.id, faris.gumelar@widyatama.ac.id, rifki.hidayattulloh@widyatama.ac.id
}

\begin{abstract}
Abstrak
Sebuah perusahaan dibangun tentulah dengan tujuan yang jelas, yaitu untuk mendapatkan keuntungan sebanyak-banyaknya, namun hal ini tidak serta merta dapat dicapai dengan mudah, banyak hal yang perlu diperhatikan oleh perusahaan untuk dapat mencapai tujuan tersebut. Salah satu aspek yang dapat memengaruhi pendapatan perusahaan adalah kepuasan pelanggan atas produk-produk yang dihasilkan, dimana kualitas produk yang dihasilkan perlu diperhatikan karena hal ini berbanding lurus dengan kepuasan pelanggan. Untuk mencapai kepuasan pelanggan, banyak hal yang dapat dilakukan oleh perusahaan, salah satunya adalah penerapan Total Quality Management (TQM) seperti yang dilakukan oleh PT.X, dimana penerapan TQM ini bertujuan untuk meningkatkan daya saing yang dilakukan dengan perbaikan secara terus-menerus sehingga hal ini dapat memengaruhi kinerja kayawan yang juga berbanding lurus dengan kualitas produk dan pendapatan perusahaan. Penelitian ini dilakukan untuk membuktikan apakah penerapan TQM yang dilakukan oleh PT.X memengaruhi kinerja kaaryawan atau tidak. Pendekatan yang dilakukan dalam penelitian ini menggunakan analisis regresi linier, dimana data yang dipakai merupakan data primer yang didapatkan dari kuisioner yang dibagikan kepada beberapa responden. Hasil penelitian menunjukkan bahwa variabel $\mathrm{X}$ berpengaruh terhadap variabel Y dengan koefisien korelasi sebesar 0,598 dan diambil keputusan bahwa penerapan TQM berpengaruh terhadap kinerja karyawan.
\end{abstract}

Kata kunci :

Total Quality Management, Kinerja Karyawan, Regresi Linier.

\begin{abstract}
A company is built of course with a clear goal, namely to get as much profit as possible, but this is not necessarily achieved easily, there are many things that companies need to pay attention to in order to achieve these goals. One of the aspects that can affect company revenue is customer satisfaction with the products produced, where the quality of the products produced needs to be considered because this is directly proportional to customer satisfaction. To achieve customer satisfaction, many things can be done by the company, one of which is the application of Total Quality Management (TQM) as done by PT. $X$, where the application of TQM aims to increase competitiveness which is done by continuous improvement so that it This can affect employee performance which is also directly proportional to product quality and company earnings. This study was conducted to prove whether the implementation of TQM by PT X affects employee performance or not. The approach used in this study uses linear regression analysis, where the data used is primary data obtained from questionnaires distributed to several respondents. The results showed that variable $X$ had an effect on variable $Y$ with a correlation coefficient of 0.598 and the decision was made that the application of TQM had an effect on employee performance.
\end{abstract}

Keywords :

Total Quality Management, Employee Performance, Linear Regression. 


\section{Pendahuluan}

Persaingan yang terjadi dalam dunia bisnis memang tidak pernah berakhir. Apapun jenis produk yang dihasilkan pastilah memiliki kompetitor dengan produk sejenis. Perusahaan harus memutar otak bagaimana caranya agar dapat terus bersaing dengan kompetitor. Hal ini juga yang menjadi perhatian PT.X sebagai salah satu perusahaan makanan dan minuman kesehatan terbesar di Indonesia. Meskipun telah memiliki nama dan brand-brand produk yang besar, namun PT.X terus berupaya untuk memuaskan pelanggan dengan kualitas produknya agar dapat terus mempertahankan eksistensinya di kalangan masyarakat.

PT.X yang merupakan produsen makanan dan minuman yang berdiri sejak tahun 1982, telah memiliki banyak produk unggulan yang bertahan hingga saat ini. PT.X dengan visinya yaitu memberikan nutrisi terbaik bagi setiap stase kehidupan, terus berupaya untuk mempertahankan kepercayaan masyarakat dengan meningkatkan kualitas produk yang dihasilkan. Salah satu upaya yang dilakukan oleh PT.X adalah dengan menerapkan Total Quality Management (TQM), dimana TQM merupakan suatu cara yang dilakukan untuk dapat meningkatkan performansi perusahaan secara terusmenerus (Gaspersz, 2001).

Penelitian dilakukan dengan tujuan untuk menganalisis pengaruh penerapan TQM terhadap kinerja karyawan melalui pendekatan analisis regresi yang merupakan analisis yang digunakan untuk mengukur hubungan statistik antar 2 variabel atau lebih. Data yang digunakan dalam penelitian merupakan data primer yang dikumpulkan dari kuisioner yang dibagikan pada responden. Responden sendiri merupakan karyawan laboratorium pada PT.X yang berjumlah 25 orang. Hasil yang diharapkan dari penelitian adalah perusahaan dapat mengevaluasi penerapan $T Q M$ yang selama ini telah dijalankan.

\section{KAJIAN LITERATUR}

Sama halnya dengan istilah keilmuan yang lain, para ahli juga memberikan definisinya masing-masing terhadap TQM. Menurut Tjiptono, TQM merupakan cara untuk menjalankan usaha dengan memaksimumkan daya saing organisasi melalui perbaikan terus-menerus atas produk, jasa, manusia, proses dan lingkungan (Tjiptono, 1995). Sedangkan
Hansen dan Mowen mengatakan bahwa TQM merupakan perbaikan berkelanjutan yang sifatnya mendasar yang dilakukan untuk mengembangkan proses manufaktur yang sempurna (Hansen \& Mowen, 2009). Pendapat lain yang dikemukakan oleh Ibrahim, $T Q M$ adalah sebuah manajemen yang menaungi semua sumber daya yang ada dalam perusahaan untuk menghasilkan produk atau jasa berkualitas demi memenuhi permintaan dan kepuasan pelanggan secara terus-menerus guna kelangsungan hidup perusahaan yang efisien (Ibrahim, 2000). Dalam hal ini dapat diambil kesamaan bahwa TQM merupakan suatu cara yang dilakukan perusahaan untuk mencapai kepuasan pelanggan dengan memberikan kualitas produk yang baik dengan cara continuous improvement.

Sepuluh karakteristik TQM yang dikenalkan oleh Goetsch dan Davis adalah sebagai berikut:

1. Fokus pada pelanggan. Pelanggan yang dimaksud ada 2 yaitu internal dan eksternal. Pelanggan internal merupakan pelanggan yang berperan dalam menentukan kualitas tenaga kerja, sedangkan pelanggan eksternal merupakan pelanggan yang menentukan kualitas produk atau jasa yang diberikan.

2. Obsesi terhadap kualitas. Berdasarkan kualitas yang telah ditentukan oleh pelanggan internal dan eksternal, perusahaan harus terobsesi untuk memenuhi atau bahkan melebihi kualitas yang telah ditentukan. Hal ini berlaku untuk semua karyawan dalam setiap level untuk berusaha melaksanakan setiap aspek pekerjaan berdasarkan perspektif.

3. Pendekatan ilmiah. Untuk mendesain pekerjaan, perlu dilakukan pendekatan ilmiah yang berkaitan dengan desain pekerjaan tersebut untuk membantu pengambilan keputusan.

4. Komitmen jangka panjang. Perusahaan harus mampu berkomitmen dalam menjalankan $T Q M$ agar budaya baik dari TQM dapat berjalan dengan sukses.

5. Kerjasama tim. Perusahaan yang menerapkan $T Q M$, menjaga hubungan antar karyawan dalam perusahaan maupun dengan pemasok, lembaga pemerintah dan masyarakat sekitar.

Niken Septiani Kurnia, Raden Faris Gumelar, Rifki Hidayattulloh 
6. Perbaikan secara berkesinambungan. Kualitas produk atau jasa yang dihasilkan dapat memengaruhi kepuasan pelanggan, dan hal ini dapat dicapai dengan perbaikan secara berkesinambungan.

7. Pendidikan dan pelatihan. Perlu adanya Pendidikan dan pelatihan yang disediakan oleh perusahaan untuk menunjang keterampilan karyawan.

8. Kebebasan yang terkendali. Keterlibatan karyawan dalam pengambilan keputusan merupakan salah satu karakteristik yang ada dalam TQM, namun kebebasan dari keterlibatan karyawan ini adalah hasil dari pengendalian yang terencana dan terlaksana dengan baik.

9. Kesatuan tujuan. Setiap organisasi diharapkan memiliki satu tujuan yang sama agar $T Q M$ dapat diterapkan dengan baik.

10. Adanya keterlibatan dan pemberdayaan karyawan. Dengan melibatkan praktisi yang ada di lapangan, dapat meningkatkan kemungkinan dihasilkannya keputusan, rencana ataupun perbaikan yang baik. (Goetsch \& Davis, 1995).

10 karakteristik $T Q M$ yang telah dijelaskan di atas juga merupakan hal-hal apa saja yang dapat dipengaruhi dari diterapkannya $T Q M$ di perusahaan. Salah satu aspek yang pasti terpengaruh dari penerapan TQM adalah kinerja karyawan. Dimana kinerja karyawan adalah yang mempengaruhi seberapa banyak mereka memberi kontribusi kepada organisasi. Banyak ahli yang telah menjelaskan definisi dari kinerja karyawan ini, berikut adalah beberapa di antaranya:

Kinerja adalah hasil kerja yang dapat dicapai oleh seseorang atau kelompok orang dalam suatu perusahaan sesuai dengan wewenang dan tanggung jawab masing-masing dalam upaya pencapaian tujuan organisasi secara ilegal, tidak melanggar hukum dan tidak bertentangan dengan moral dan etika. (Afandi, 2018)

Kinerja (prestasi kerja) adalah hasil kerja secara kualitas dan kuantitas yang dicapai oleh seseorang pegawai dalam melaksanakan tugasnya sesuai dengan tanggung jawab yang diberikan kepadanya. (Mangkunegara, 2009).
Kinerja adalah implementasi dari rencana yang telah disusun tersebut. Implementasi kinerja dilakukan oleh sumber daya manusia yang memiliki kemampuan, kompetensi, motivasi, dan kepentingan. Bagaimana organisasi menghargai dan memperlakukan sumber daya manusianya akan memengaruhi sikap dan perilakunya dalam menjalankan kinerja. (Wibowo, 2010)

Faktor yang mempengaruhi pencapaian kinerja adalah faktor kemampuan (ability) dan faktor motivasi (motivation).

1. Faktor Kemampuan (Ability). Secara psikologis, kemampuan (ability) terdiri dari kemampuan potensi (IQ) dan kemampuan reality (knowledge + skill). Artinya, pimpinan dan pegawai yang memiliki IQ di atas rata-rata (IQ 110-120) apalagi IQ superior, very superior, gifted dan genius dengan pendidikan yang memadai untuk jabatannya dan terampil dalam mengerjakan pekerjaan seharihari, maka akan lebih mudah mencapai kinerja maksimal.

2. Faktor Motivasi (Motivation). Motivasi diartikan suatu sikap (attitude) pimpinan dan pegawai terhadap situasi kerja (situation) di lingkungan organ isasinya. Mereka yang bersikap positif ( $p r o$ ) terhadap situasi kerjanya akan menunjukkan motivasi kerja tinggi dan sebaliknya jika mereka bersikap negatif (kontra) terhadap situasi kerjanya akan menunjukkan motivasi kerja yang rendah. Situasi kerja yang dimaksud mencakup antara lain hubungan kerja, fasilitas kerja, iklim kerja, kebijakan pimpinan, pola kepemimpinan kerja dan kondisi kerja.

Analisis regresi linier sederhana merupakan salah satu metode regresi yang dapat dipakai sebagai alat inferensi statistik untuk menentukan pengaruh sebuah variabel bebas (independen) terhadap variabel terikat (dependen). Uji Regresi linear sederhana ataupun regresi linier berganda pada intinya memiliki beberapa tujuan, yaitu:

1. Menghitung nilai estimasi rata-rata dan nilai variabel terikat berdasarkan pada nilai variabel bebas.

2. Menguji hipotesis karakteristik dependensi

3. Meramalkan nilai rata-rata variabel bebas dengan didasarkan pada nilai variabel bebas diluar jangkaun sample.

Pada analisis regresi sederhana dengan menggunakan SPSS ada beberapa asumsi dan 
persyaratan yang perlu diperiksa dan diuji, beberapa di antaranya adalah:

1. Variabel bebas tidak berkorelasi dengan disturbance term (Error). Nilai disturbance term sebesar 0 atau dengan simbol sebagai berikut: $\mathrm{E}(\mathrm{U} / \mathrm{X})=0$

2. Jika variabel bebas lebih dari satu, maka antara variabel bebas (explanatory) tidak ada hubungan linier yang nyata

3. Model regresi dikatakan layak jika angka signifikansi pada ANOVA sebesar < 0.05, Predictor yang digunakan sebagai variabel bebas harus layak. Kelayakan ini diketahui jika angka Standard Error of Estimate < Standard Deviation

4. Koefisien regresi harus signifikan. Pengujian dilakukan dengan Uji T. Koefesien regresi signifikan jika $\mathrm{T}$ hitung $>\mathrm{T}$ tabel (nilai kritis)

5. Model regresi dapat diterangkan dengan menggunakan nilai koefisien determinasi $(\mathrm{KD}=\mathrm{R}$ Square $\mathrm{x} 100 \%)$ semakin besar nilai tersebut maka model semakin baik. Jika nilai mendekati 1 maka model regresi semakin baik

6. Residual harus berdistribusi normal

7. Data berskala interval atau rasio

8. Kedua variabel bersifat dependen, artinya satu variabel merupakan variabel bebas (variabel predictor) sedang variabel lainnya variabel terikat (variabel response).

(Uyanto, 2009) menyatakan bahwa "uji t dua sampel independen (independent samples t-test) digunakan untuk membandingkan selisih dua purata (mean) dari dua sampel yang independen dengan asumsi data berdistribusi normal".

(Sumanto, 2014) menyatakan bahwa "Sampel independen adalah sampel yang dibentuk secara random, dibentuk tanpa melalui penjodohan".

Menurut (Sugiyono, 2005), untuk melakukan uji beda terdapat beberapa rumus t-test yang digunakan untuk pengujian, berikut ini pedoman penggunaannya:

1. Bila jumlah sampel $\mathrm{n} 1=\mathrm{n} 2$, dan varians homogen $\left(\sigma 1^{2}=\sigma 2^{2}\right)$ maka dapat digunakan rumus t-test baik untuk Separated maupun Pooled varians. Untuk melihat harga t-tabel digunakan $\mathrm{dk}=\mathrm{n} 1+\mathrm{n} 2-2$.

2. Bila $\mathrm{n} 1 \neq \mathrm{n} 2$, varians homogen $\left(\sigma 1^{2}=\sigma 2^{2}\right)$, dapat digunakan dengan Pooled varians. Derajat kebebasan $(\mathrm{dk})=\mathrm{n} 1+\mathrm{n} 2-2$.

3. Bila $\mathrm{n} 1=\mathrm{n} 2$, varians tidak homogen $\left(61^{2} \neq\right.$ $62^{2}$ ), dapat digunakan dengan Separated dan Pooled varians. Dengan $\mathrm{dk}=\mathrm{n} 1-1$ atau $\mathrm{n} 2$ -1 . jadi dk bukan $+\mathrm{n} 2-2$.

4. Bila $\mathrm{n} 1 \neq \mathrm{n} 2$ dan varians tidak homogen $\left(\sigma 1^{2}\right.$ $\neq 62^{2}$ ). Untuk ini digunakan $t$-test dengan Separated varians. Harga t sebagai pengganti $\mathrm{t}$-tabel dihitung dari selisih harga $\mathrm{t}$-tabel dengan $\mathrm{dk}(\mathrm{n} 1-1)$ dan $\mathrm{dk}(\mathrm{n} 2-1)$ dibagi dua, dan kemudian ditambahkan dengan harga t yang terkecil.

\section{Pengumpulan dan Pengolahan DATA}

Data yang digunakan dalam penelitian merupakan data primer yang dikumpulkan melalui kuisioner yang dibagikan kepada 25 sampel karyawan laboratorium sebagai responden. Responden kemudian menjawab 11 pertanyaan yang sudah disediakan, dimana pertanyaan tersebut berkaitan dengan penerapan $T Q M$ pada perusahaan terhadap kinerja karyawan dan berskala Likert dengan 5 poin penilaian yaitu 1 (Sangat Tidak Setuju), 2 (Tidak Setuju), 3 (Tidak Tahu), 4 (Setuju) dan 5 (Sangat Setuju). Data yang telah terkumpul kemudian diolah menggunakan software SPSS untuk melihat seberapa berpengaruh variabel $\mathrm{X}$ yaitu penerapan $T Q M$ terhadap variabel $\mathrm{Y}$ yaitu kinerja karyawan. Setelah didapatkan nilai regresi dari kedua variabel yang dibandingkan tersebut, kemudian dilakukan pengujian hipotesis yang dilakukan menggunakan Uji t. adapun hipotesis yang digunakan dalam penelitian ini adalah sebagai berikut:

\footnotetext{
$\mathrm{H}_{1}$ : Penerapan Total Quality Management berpengaruh secara signifikan terhadap kinerja karyawan laboratorium

$\mathrm{H}_{0}$ : Penerapan Total Quality Management tidak berpengaruh secara signifikan terhadap kinerja karyawan laboratorium
} 
Dengan tingkat signifikansi 5\%, keputusan yang diambil akan berdasarkan perbandingan nilai $t_{\text {hitung }}$ dan nilai $t_{\text {tabel }}$ dengan ketentuan sebagai berikut:

Jika nilai $\mathrm{t}_{\text {hitung }}>$ nilai $\mathrm{t}_{\text {tabel, }}$ maka $\mathrm{H}_{0}$ ditolak artinya koefisien regresi signifikan.

Jika nilai $\mathrm{t}_{\text {hitung }}<$ nilai $\mathrm{t}_{\text {tabel, }}$ maka $\mathrm{H}_{0}$ diterima artinya koefisien regresi tidak signifikan.

Berikut adalah hasil pengolahan data menggunakan software SPSS:

\begin{tabular}{|c|c|c|c|c|c|c|}
\hline \multicolumn{7}{|c|}{ Coefficients $^{a}$} \\
\hline & & \multicolumn{2}{|c|}{ Unstandardized Coefficients } & \multirow{2}{*}{$\begin{array}{l}\text { Standardized } \\
\text { Coefficients } \\
\text { Beta }\end{array}$} & \multirow[b]{2}{*}{$t$} & \multirow[b]{2}{*}{ Sig. } \\
\hline \multicolumn{2}{|c|}{ Model } & B & Std. Error & & & \\
\hline \multirow[t]{2}{*}{1} & (Constant) & 9.890 & 3.250 & & 3.043 & .006 \\
\hline & TOM & .451 & .126 & .598 & 3.582 & .002 \\
\hline
\end{tabular}

Gambar 1. Output SPSS (1)

(Sumber: Pengolahan Data)

\begin{tabular}{|l|l|c|c|c|}
\hline \multicolumn{6}{|c|}{ Model Summary } \\
& & & Adjusted R & Std. Error of \\
Model & R & R Square & Square & the Estimate \\
\hline 1 & $.598^{\text {a }}$ & .358 & .330 & 1.515 \\
\hline \multicolumn{2}{|c|}{ a. Predictors: (Constant), TQM } & \\
\hline
\end{tabular}

Gambar 2. Output SPSS (2)

(Sumber: Pengolahan Data)

Berdasarkan data yang diolah tersebut, model regresi linier yang terbentuk adalah

$$
Y=9,890+0,451 X
$$

Dengan interpretasi data sebagai berikut:

1. Koefisien regresi variabel $X$ adalah sebesar 0,451 yang artinya jika variabel $\mathrm{X}$ ditingkatkan 1 maka akan mempengaruhi variabel $\mathrm{Y}$ sebanyak 0,451 kali.

2. Koefisien determinasi atau R-Square sebesar 0,358 yang artinya $35,8 \%$ variabel $\mathrm{X}$ berpengaruh terhadap variabel $\mathrm{Y}$.

3. Koefisien korelasi (R) menunjukkan seberapa erat hubungan langsung antara variabel $\mathrm{X}$ terhadap variabel Y. Literatur yang dapat dijadikan sebagai pedoman keeratan hubungan variabel dikemukaan oleh Sugiyono (2007) yaitu:

$0,00-0,199=$ sangat rendah

$0,20-0,399=$ rendah
$0,40-0,599=$ sedang

$0,60-0,799=$ kuat

$0,80-1,000=$ sangat kuat

Berdasarkan literatur dan hasil pengolahan data tersebut didapatkan nilai $\mathrm{R}$ sebesar 0,598 yang artinya secara statistika hubungan antara penerapan $T Q M$ cukup berpengaruh terhadap kinerja karyawan.

Pengambilan keputusan dilakukan dengan membandingkan nilai signifikansi yang didapatkan yaitu sebesar $0,002<0,05$ serta membandingkan nilai $t_{\text {hitung }}$ sebesar 3,582 $>t_{\text {tabel }} 2,069$. Sesuai dengan hipotesis yang sebelumnya telah ditentukan, jika nilai $\mathrm{t}_{\text {hitung }}>$ nilai $\mathrm{t}_{\text {tabel }}$ maka $\mathrm{H}_{0}$ ditolak, artinya variabel $\mathrm{X}$ berpengaruh terhadap variabel $\mathrm{Y}$.

\section{KESIMPULAN DAN SARAN}

\section{A. Kesimpulan}

Berdasarkan permasalahan, tujuan dan hipotesis dan hasil analisis tentang pengaruh TQM terhadap kinerja karyawan di laboratorium PT. X dapat disimpulkan sebagai berikut:

1) Hasil analisis pengaruh $T Q M$ terhadap kinerja karyawan di laboratorium PT. X menggunakan software SPSS didapatkan nilain koefisien regresi variable $\mathrm{X}$ sebesar 0,451 artinya variabel $\mathrm{Y}$ akan meningkat sebanyak 0,451 kali setiap variabel $\mathrm{X}$ ditingkatkan.

2) Hasil nilai $R$ sebesar 0,598 yang didapat dari hasil pengolahan data Model Summary menggunakan software SPSS atau 59,8\%, yang artinya secara statistika hubungan antara penerapan $T Q M$ dengan kinerja karyawan cukup berpengaruh karena termasuk kategori sedang.

3) Hasil nilai signifikansi didapatkan sebesar 0,002 $<0,05$ serta nilai $t_{\text {hitung }}$ sebesar 3,582 $>t_{\text {tabel }} 2,069$. Maka merujuk hipotesis yang sebelumnya sudah ditentukan, jika nilai $\mathrm{t}_{\text {hitung }}>$ nilai $\mathrm{t}_{\text {tabel }}$ maka $\mathrm{H}_{0}$ ditolak, yang berarti variabel $\mathrm{X}$ yaitu $T Q M$ berpengaruh secara siginifikan terhadap variabel $\mathrm{Y}$ yaitu kinerja karyawan.

B. Saran

Berdasarkan hasil penelitian, terdapat beberapa saran untuk menanggapi kesimpulan tersebut, yaitu sebagai berikut: 
1) Pada pengumpulan data, jawaban dari kuisioner yang dipilih oleh responden (karyawan) harus sesuai dengan yang responden ketahui tidak disarankan atau diberitahu oleh responden lainnya agar jawaban responden sesuai dengan yang diharapkan oleh peneliti.

2) Perlu dilakukan penambahan jumlah responden saat melakukan pengumpulan data, karena untuk lebih mengetahui lagi seberapa besar pengaruh $T Q M$ terhadap kinerja karyawan.

3) Pada penelitan selanjutnya dapat dikembangkan atau ditambah variabel lain yang juga merupakan pengaruh dari diterapkannya $T Q M$ di perusahaan sehingga dapat menjadi bahan evaluasi perusahaan di masa mendatang.

\section{REFERENSI}

Ibrahim. 2000. TQM Total Quality Management Panduan Untuk Menghadapi Persaingan Global. Jakarta: Djambatan.

Hansen dan Mowen. 2009. Akuntansi Manajerial, Buku 1 Edisi 8. Jakarta: Salemba Empat.

Tjiptono, Fandy. 1995. Strategi Pemasaran. Yogyakarta: Andi Offset.

Goetsch, DL. 1995. Implemenatting to Total Quality. New Jersey: Prentice Hall International, Inc.

Gaspersz, Vincent. 2001. Total Quality Management. Jakarta: Gramedia Pustaka Utama.

Uyanto, Stanislaus S. 2009. Pedoman Analisis Data dengan SPSS. Graha Ilmu. Yogyakarta.

Sumanto. 2014. Statistika Terapan. Yogyakarta: CAPS (Center of Academic Publishing Service)

Hidayat, Anwar. 2012. Regresi Linear Sederhana dengan SPSS

Mangkunegara, Anwar Prabu. 2009. Manajemen Sumber Daya Manusia Perusahaan. Cetakan Ketiga. Bandung: PT. Remaja Rosdakarya. 